\title{
Trends in, and transitions to, institutional residence among older people in England and Wales, 1971-91
}

\author{
Emily Grundy, Karen Glaser
}

\begin{abstract}
Objectives-To compare transitions from private households to institutions between 1971-81 and 1981-91 among elderly people and see whether (1) differentials in the risk of institutionalisation changed and (2) whether the risk was higher in the second period.
\end{abstract}

Design-Cross sequential analysis of data from the Office of National Statistics longitudinal study, a record linkage study which included individual level data from three national censuses, (1971, 1981, and 1991) and linked vital registration data.

Subjects-Altogether 26400 people aged 65 and over in 1971-81 and 32500 persons aged 65 and over in 1981-91. These samples represent $1 \%$ of the population of England and Wales.

Results-In both periods models including age, housing tenure, and marital status or household/family type terms fitted the data reasonably well. The effect of age was stronger in the second decade, while that of marital status was reduced. The risk of transition to an institution was nearly $33-52 \%$ higher in the second decade after controlling for these factors.

Conclusions-During the 1980 s the availability of state financed institutional care increased substantially; a growth which the 1990 NHS and Community Care Act was designed to reverse. Increased access to institutional care undoubtedly is one factor underlying the higher transition rate to institutions observed in 1981-91 than for the previous decade. During 1981-91, transitions to live with relatives also declined substantially. It is not clear whether this simply represents the continuation of a previous trend or whether the increased availability of institutional care led to some substitution for family care. Either interpretation has worrying implications for policy makers keen to promote care in the community.

King's College,

London, Cornwall

House, Waterloo Road, London SE1 8WA

E Grundy

K Glaser

Correspondence to: Dr E Grundy.

Accepted for publication March 1997

\section{(F Epidemiol Community Health 1997;51:531-540)}

In Britain, much of the rest of Europe, and in North America the number and proportion of very old people, who are most at risk of institutional residence, is growing rapidly. Institutional care is costly, and the question of how to fund it has become a major issue of public debate and concern both for providers and older people and their relatives. ${ }^{12}$ While only a minority of older people live in institutions, in "older old" age groups this minority is a large one. In England and Wales in 1991, over a quarter of women aged 85 years and over lived in non-private households (the official term used to denote communal establishments, of whatever type). ${ }^{3}$ For never-married women in this age group, well over a third of whom lived in non-private households, this was the second most common type of living arrangement (after living alone). ${ }^{4}$ Information on trends in institutionalisation, and on variations in the propensity to enter institutional care, is clearly needed for service planning and as a basis for identifying possible preventive interventions. It is also essential to have information on the extent of institutional residence to inform analyses of trends and differentials in the health status of the older population. Most surveys include only the population in private households-that is those who live "in the community" in ordinary households (of all tenure types). Prevalence studies based on the private household population alone underestimate the extent of health impairments in the total population as the unhealthiest are excluded; if the relative size of this excluded group changes in ways that are not allowed for the extent of bias in these estimates will also vary. Similarly analyses of differentials in health status may be biased. For example, some studies of marital status differentials in health status based on the private household population indicate that nevermarried women enjoy as good or even better health in older age groups than their married counterparts, a finding tentatively ascribed to their well developed social support networks. ${ }^{5}$ However, analyses of British data have shown that the apparent reduced health disadvantage of the never-married in older, compared with younger, age groups disappears when the total population, rather than the private household population alone, is considered. ${ }^{6}$

Changes in the proportion of older people living in non-private households (predominantly institutions of various kinds) have attracted some attention ${ }^{4-10}$ but most analysts of trends in the living arrangements of older people have focused principally on changes in the composition of the private household population; particularly the increase in solitary living and decrease in co-residence with kin other than the nuclear family which has been so notable in the developed world. ${ }^{11-17}$ There is, however, a substantial amount of published 
information, predominantly from the United States, on the characteristics of the population in institutions and on differentials in transitions to institutions. In general, both cross sectional and longitudinal analyses have shown relationships between institutionalisation and demographic characteristics, such as age, sex, marital status, parity, and ethnicity; indicators of health status, such as functional disability and needs for assistance; and socioeconomic variables, such as income and education. ${ }^{18-22}$ As all these variables tend to be associated with each other, identifying the relative importance of each is complex and a number of studies have reported conflicting results on, for example, the effect of number of children on the risk of institutionalisation. ${ }^{18} 2023-26$ Results from cross sectional studies are also, in some cases, at variance with those from longitudinal ones as the former may reflect the effect on institutionalisation on, for example, income rather than a predisposing risk. ${ }^{2227-29}$

British research on variations and trends in institutionalisation is more restricted. The non-private household population is excluded from most regular government surveys, which leaves the census and the census based Office of National Statistics longitudinal study (LS) as the only national source, apart from one off surveys. Townsend and Wedderburn's pioneering work in the early 1960 s suggested that poor housing was then a risk factor for entry to institutional care and showed that the nevermarried and childless widowed were over represented in institutions, as were men from unskilled manual occupational backgrounds. ${ }^{30}$ Since then there have been a few national and several local studies of those in institutions, ${ }^{31-34}$ including two parallel surveys of disabled adults in private households and communal establishments carried out by the then Office of Population Censuses and Surveys (OPCS) in the mid-1980s. ${ }^{35}$ This work showed a strong association between disability and residence in a communal establishment, but among those aged 70 and over, $40 \%$ of respondents even in the most severely disabled groups lived in private households highlighting the fact that disability is not the sole determinant of entry to institutional care. Previous analyses of longitudinal data in the $\mathrm{LS}^{143637}$ showed that age, marital status, housing tenure, household type, and area of residence were associated with differentials in transitions between private and non-private households between 1971 and 1981. Women who in 1971 were tenants in the privately rented sector, for example, had nearly twice the risk of being a resident in an institution in 1981 than owner occupiers (controlling for age and marital status). The subsequent mortality of those who moved to institutions was much higher than that of those who remained in private households, indicating the importance of health status as a factor in institutionalisation.

The addition of 1991 census data to the LS means that it is now possible to extend this previous work to examine the period 1981-91 and compare this with the earlier decade. This extension is timely for a number of reasons.
KEY POINTS

- Transition rates to institutions were much higher for older people in 1981-91 than in 1971-81.

- Transition rates to live with relatives were much lower in the second period.

- In both periods, single people and those living in privately rented housing had the highest rate of institutionalisation.

Firstly, as noted above, the provision and funding of long term care is now a major issue of public debate. Secondly, there have been changes in the composition of the older population, which might be expected to have influenced both the extent of institutionalisation and differentials between groups. The numbers of never- married women and childless women, for example, have fallen due to the higher nuptiality and fertility of those born in the inter-war and immediate post second world war decades in comparison with those born earlier (and later) in the 20th century. It has been estimated that $33 \%$ of women born in 1902-06 were childless at age 45-49, compared with $21 \%$ of those born in 1920 and only $14 \%$ of the 1930 birth cohort. ${ }^{4}$ Cross sectional LS data show that $16 \%$ of women aged 80 and over in 1971 were never-married, compared with $14 \%$ in 1981 and $12 \%$ in 1991 . The prevalence of widowhood in younger elderly age groups has also fallen slightly due to a recent narrowing of sex differences in death rates at older ages. ${ }^{4}$ These changes imply an increase in the availability of kin but there has been no associated increase in the extent of co-residence. On the contrary, there have been marked increases in the proportions living alone, and continuing steep declines in the proportions living with relatives. In England and Wales in $1971,27 \%$ of men and $31 \%$ of women aged 85 and over lived in complex households (with relatives); by 1991 these proportions had fallen to $10 \%$ and $13 \%$ respectively. ${ }^{4}$ Apart from these demographic changes, the housing and housing tenure distribution of the older population has also changed, with continuing declines in the proportion of tenants in the private and, more recently, the public, rented sectors and improvements in housing standards. ${ }^{38}$

Thirdly, changes in the administration of social security benefits in the 1980 s effectively increased the availability of state financed residential and nursing home care. Before the early 1980 s, most long term care was provided in the public sector either in NHS geriatric and psychiatric units or by local authorities in their own residential homes, or through "sponsorship" of residents in voluntary or, less often, private (for profit) homes. From the early 1980 s, however, local offices of the then Department of Social Security began making "board and lodging" allowances to pay for care in non-statutory residential and nursing homes which, together with other allowances payable to those with needs for assistance on grounds of disability, meant that the full cost of care was 

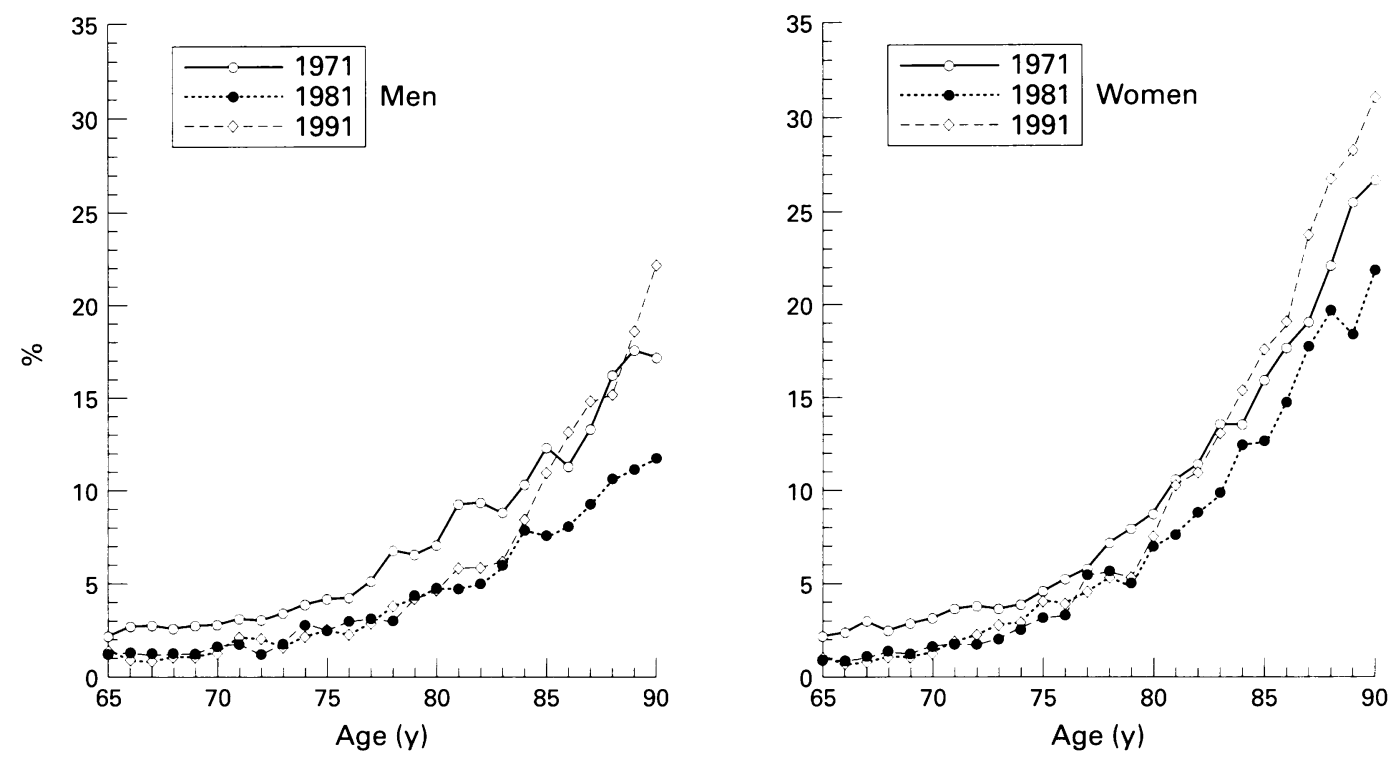

Figure 1 Proportions of older people living in institutions in relation to gender, 1971-91.

available from public sources for elderly people who qualified on grounds of income and savings. ${ }^{30}$ No prior medical or social work assessment was required. While the number of beds in local authority homes and in the NHS sector continued to decline, ${ }^{41}$ this was more than offset by huge growth in the private sector. The number of long term care places in private sector residential homes, for example, increased from 39253 in 1981 to 155315 in $1991,{ }^{1}$ and expenditure on income support for those in residential and nursing homes increased from some $£ 10$ million in $1980-81$ to $£ 1000$ million in 1988 (1988 prices). ${ }^{42}$ In response to this, national limits on the amount of fees that would be paid were set in 1985 . This was followed by major legislative change in the early 1990s (the 1990 NHS and Community Care Act which became fully operational in 1993). This returned responsibility for assessing needs for long term care and purchasing it to local authorities. The effect of these most recent changes, however, post dates the period under consideration here.

Finally, and most importantly, rates of institutional residence, as well as numbers in institutional care, have increased in some age groups in the USA ${ }^{9}$ and, more recently, Britain. Figures 1 and 2, based on cross sectional LS data, show for older men and women respectively the proportions resident in institutions in 1971,1981 , and 1991 by single years of age. At all ages, this proportion was lower in 1981 than it had been 10 years earlier; however, between 1981 and 1991 rates of institutional residence rose substantially in older age groups, and by 1991 were higher among those aged 85 and over than in either of the two preceding censuses.

In this paper we present a comparative analysis of transitions from private to nonprivate households during the periods 1971-81

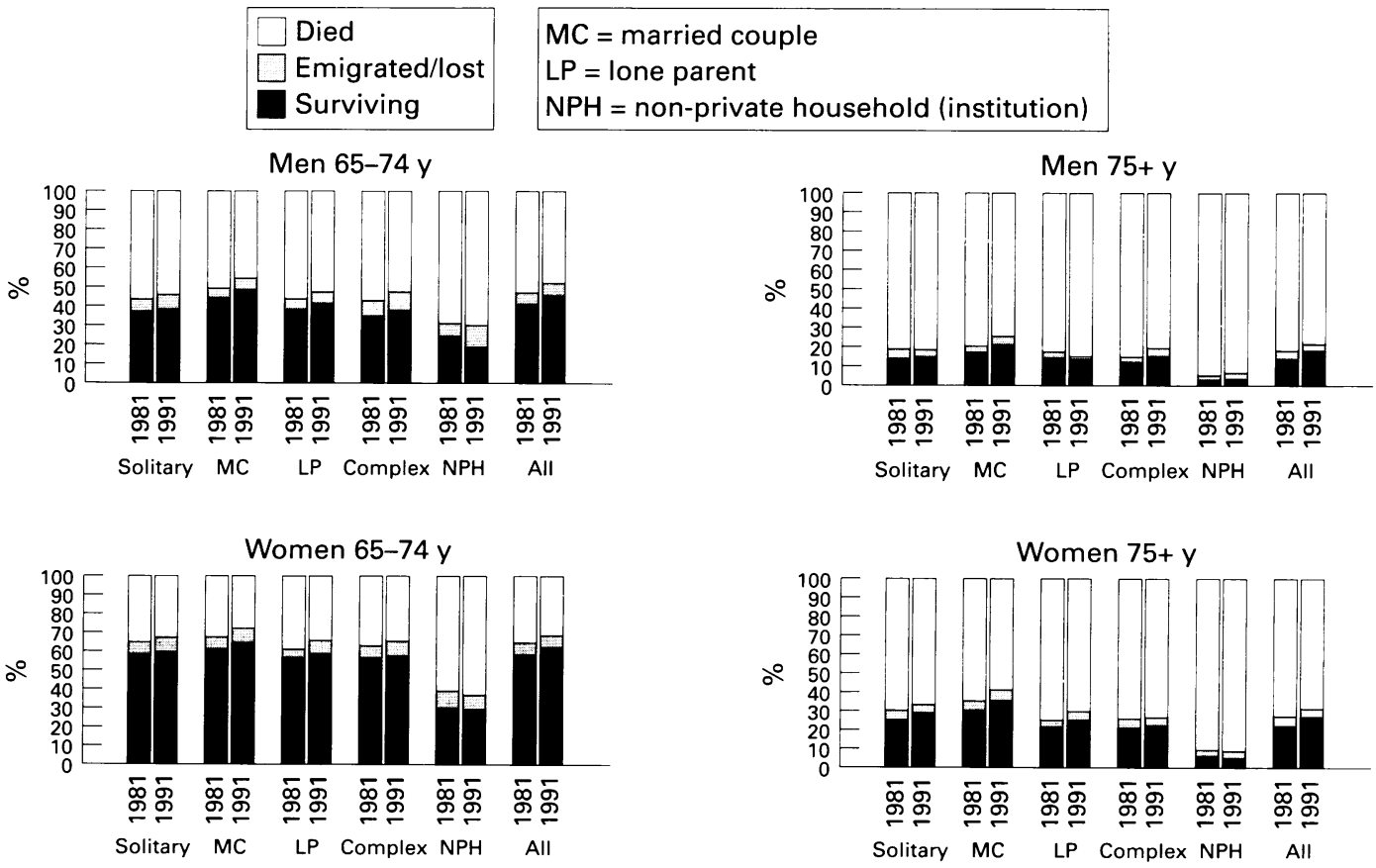

Figure 2 Outcome in 1991-81 in relation to age, gender, and family household type 10 years earlier. 
and 1981-91. The major research questions we address are as follows:

- Did differentials in the risk of institutionalisation change between these two periods? and

- Was the risk of institutionalisation higher in the second period after controlling for sociodemographic risk factors?

\section{Methods}

The LS, the data source used here, is based on a $1 \%$ sample of the population of England and Wales enumerated in the 1971 census. Sample members were selected on the basis of birthday and traced in the NHS Central Register (NHSCR). Record linkage was used to add information from the vital registration of events, such as death, and data from the 1981 and 1991 census records of surviving sample members. The sample has been maintained through the addition of $1 \%$ of new births and of immigrants. Further details of the data set, including linkage rates, are given elsewhere. ${ }^{43}$

The strengths of the LS are the large sample size, and the availability of micro-data for more than one point in time. Against these strengths must be set the long intervals between census data capture points and the relatively limited range of variables available. Income data, for example, are not collected and the only information on education relates to higher level qualifications which very small proportions of older people have. Housing tenure and access to a car thus represent the main socioeconomic indicators for those not at work; both have been shown to be strongly associated with mortality differentials ${ }^{44}{ }^{45}$ and with income. ${ }^{38}$ In the very elderly population, however, access to a car is strongly associated with marital status and household type, and is thus a poor indicator of personal resources. A question on health status was included in 1991 but not in 1981 or 1971 .

\section{DEFINITIONS}

All the analysis of LS data presented here is restricted to those permanently resident at the place of enumeration. Visitors, such as those temporarily staying with relatives or in hospital for a short period, have been excluded. The definitions of private and non-private households are those used in the census. The non-private household population includes campers, vagrants, and persons enumerated on ships as well as those in institutions; however, as these former categories are negligible in size $(0.3 \%$ of the total), we generally use the terms non-private household and institution synonymously here. All types of institution, whether in the public or private sector, are included in this category. The household/family classification used is based on the standard definition of family used by the Office of National Statistics and most statistical offices. This defines a family in strictly nuclear terms to include people living with a spouse (with or without children and others); with a never-married child (whether or not a spouse is present) or with a parent if they themselves are never-married. Those living with other kin (including siblings or never-married children) or non-relatives are described here as living in "complex" households. The very small proportion living in two family households has also been allocated to this category.

\section{SAMPLE ATTRITION}

The results presented here all come from the same study, but relate to separate, although overlapping, populations. The cross sectional data shown in figures 1 and 2 are based on all sample members present in the relevant census. Thus, those aged 85+ in 1991 include the survivors of those aged $75+$ in 1981 (and $65+$ in 1971) together with new entrants (mainly immigrants from other parts of the United Kingdom and elsewhere), of the appropriate age. Longitudinal data obviously relate only to sample survivors. Figure 3 shows outcome in 1981 or 1991 by age and household/family type 10 years earlier. Attrition through death was considerable, particularly among men, but very slightly lower in the second decade reflecting improvements in mortality over the period considered. Survival was highest for those living in married couple households (who tended to be younger than others in the same broad age group) and lowest for those already in nonprivate households.

As indicated by the low rates of attrition for reasons other than death, linkage rates of sample members' census records have been high; overall linkage rates of $91 \%$ for $1971-81$ and $90 \%$ for $1981-91$ were obtained. ${ }^{43}$ However, linkage rates for the institutional population have been lower; probably because of the greater risk of misreporting of birth date. Altogether, $79 \%$ of those in communal establishments in 1971 and not recorded as dead by the 1981 census were found in that census; the equivalent proportion for the 1981-91 decade was $76 \% .{ }^{46}$ This means that the rates of transition from private to non private households reported here are probably slight underestimates.

Here we report analyses of the proportions who were in private households in 1971 but by 1981 lived in institutions and the equivalent proportions making a transition from residence in private household in 1981 to a non-private one in 1991. We refer to these transitions as institutionalisation rates, although they of course only give a partial indicator of the full extent to transitions to institutions. This is because many elderly people who moved from a private household to an institutional one during an intercensal period would have died before the next census. Initially, cross tabulations of transition data were prepared. These were further analysed using the statistical package GLIM to fit regression models to the data using a logit transformation of the proportions in institutions at the end of each decade considered (but in private households at the beginning).

\section{Results}

INSTITUTIONALISATION RATES IN RELATION TO AGE, SEX, MARITAL STATUS, AND HOUSING TENURE

Tables 1 and 2 show rates of transition to nonprivate households in 1971-81 and 1981-91 in 
Table 1 Transition rates (\%) from private to non-private households 1971-81 and 1981-91 by age, housing tenure, and marital status in men

\begin{tabular}{|c|c|c|c|c|c|c|c|c|}
\hline \multirow{3}{*}{$\begin{array}{l}\text { Age and housing tenure at } \\
\text { start of period }\end{array}$} & \multicolumn{8}{|c|}{ Marital status (at end of period) } \\
\hline & \multicolumn{2}{|l|}{ Single } & \multicolumn{2}{|l|}{ Married } & \multicolumn{2}{|c|}{ Widowed/divorced } & \multicolumn{2}{|l|}{ All } \\
\hline & $1971-81$ & 1981-91 & $1971-81$ & $1981-91$ & $1971-81$ & $1981-91$ & $1983-81$ & $1981-91$ \\
\hline \multicolumn{9}{|l|}{$65-69$ y } \\
\hline Owner occupier & 2.4 & 3.8 & 0.6 & 0.8 & 3.3 & 4.8 & 1.3 & 1.8 \\
\hline LA tenant & 6.1 & 3.1 & 1.1 & 1.3 & 4.5 & 5.2 & 2.2 & 2.6 \\
\hline Private renter & 9.3 & 9.5 & 1.0 & 0.9 & 9.3 & 7.5 & 3.8 & 3.4 \\
\hline All & 5.2 & 4.7 & 0.8 & 1.0 & 4.9 & 5.3 & 2.0 & 2.2 \\
\hline \multicolumn{9}{|l|}{$70-74$ y } \\
\hline Owner occupier & 1.9 & 11.6 & 1.7 & 2.0 & 6.0 & 8.0 & 3.4 & 4.3 \\
\hline LA tenant & (22.2) & (14.3) & 2.0 & 2.4 & 5.4 & 10.3 & 4.4 & 6.3 \\
\hline Private renter & $(16.7)$ & (17.9) & 1.8 & 2.5 & 9.4 & 9.1 & 6.2 & 6.4 \\
\hline All & 10.6 & 13.5 & 1.8 & 2.2 & 6.5 & 8.8 & 4.1 & 5.0 \\
\hline \multicolumn{9}{|l|}{$75+y$} \\
\hline Owner occupier & $(16.0)$ & (17.5) & 4.8 & 5.9 & 10.9 & 20.8 & 8.9 & 13.7 \\
\hline LA tenant & $(0.0)$ & $(27.8)$ & 1.1 & 5.6 & 14.0 & 19.0 & 8.0 & 14.8 \\
\hline Private renter & $(25.0)$ & (21.4) & 3.1 & 7.9 & 17.1 & 28.4 & 14.0 & 18.8 \\
\hline All & (17.4) & $(28.8)$ & 3.8 & 6.1 & 12.7 & 21.2 & 9.6 & 14.5 \\
\hline
\end{tabular}

LA=local authority.

relation to age, sex, and housing tenure at the start of the decade (1971 or 1981) and marital status at the end (1981 or 1991). This latter indicator of marital status was chosen as it was thought it would give a better indication of marital status at the time of a move into an institution for those still in institutions at the end of the decade. Women are shown by four age groups, but men by only three, as there were too few survivors in the 80 plus group to allow separate analysis. Rates of transition to non-private households (1971-81 and 198191) were lowest among the married and, except in the youngest age group, highest for the single (never-married). Overall, and in most of the subgroups shown in the tables, owner occupiers had the lowest rates of transition to institutions and tenants in privately rented accommodation the highest. Transition rates were generally higher in the second decade considered, although the extent of change among those in the youngest age group shown was modest. Among those aged 75 or more the difference in transition rates between the two decades was substantial.
As age, housing tenure, and marital status are all associated, multifactorial analysis is clearly needed to assess the relative importance of each of these and any effect of period (second versus first decade). This was undertaken using GLIM to fit a series of regression models to the data using a logit transformation of the proportions in institutions at the end of each decade considered (but in private households at the beginning). $\theta=\operatorname{logit} \mathrm{p}=\log \{\mathrm{p} /(1-\mathrm{p})\}$

Models were fitted to the data for men and women separately. Data subsets for each decade were analysed separately and then in combination. The independent terms were as shown in tables 1 and 2 with the addition of a dummy variable, period, for analyses of transition data for both decades.

Table 3 shows the scaled deviance and associated degrees of freedom for models fitted, together with change in deviance and degrees of freedom consequent on adding specified terms. Changes in deviance approximately follow a $\chi^{2}$ distribution (especially in large samples such as this) and may be used to give an indication of statistical significance. ${ }^{47}$ The overall fit of a

Table 2 Transition rates (\%) from private to non-private households 1971-81 and 1981-91 by age, housing tenure, and marital status in women

\begin{tabular}{|c|c|c|c|c|c|c|c|c|}
\hline \multirow{3}{*}{$\begin{array}{l}\text { Age and housing tenure at } \\
\text { start of period }\end{array}$} & \multicolumn{8}{|c|}{ Marital status (at end of period) } \\
\hline & \multicolumn{2}{|l|}{ Single } & \multicolumn{2}{|l|}{ Married } & \multicolumn{2}{|c|}{ Widowed/divorced } & \multicolumn{2}{|l|}{ All } \\
\hline & $1971-81$ & $1981-91$ & $1971-81$ & $1981-91$ & $1971-81$ & $1981-91$ & $1971-81$ & $1981-91$ \\
\hline \multicolumn{9}{|l|}{$65-69 y$} \\
\hline Owner occupier & 4.5 & 5.6 & 0.7 & 1.0 & 3.8 & 3.9 & 2.9 & 2.9 \\
\hline LA tenant & 3.4 & 11.8 & 1.0 & 2.4 & 4.6 & 4.5 & 3.6 & 4.5 \\
\hline Private renter & 2.7 & 6.9 & 1.1 & 2.8 & 4.6 & 4.2 & 3.6 & 4.2 \\
\hline All & 3.9 & 7.5 & 0.9 & 1.5 & 4.2 & 4.1 & 3.2 & 3.6 \\
\hline \multicolumn{9}{|l|}{$70-74 y$} \\
\hline Owner occupier & 9.7 & 12.3 & 1.8 & 3.1 & 6.5 & 9.3 & 6.1 & 8.1 \\
\hline LA tenant & 15.6 & 16.7 & 1.8 & 3.9 & 8.3 & 11.3 & 7.8 & 10.6 \\
\hline Private renter & 15.6 & 19.7 & 0.0 & 4.9 & 8.8 & 15.6 & 8.8 & 14.3 \\
\hline All & 12.1 & 14.6 & 1.5 & 3.5 & 7.5 & 10.9 & 7.1 & 9.7 \\
\hline \multicolumn{9}{|l|}{$75-79 y$} \\
\hline Owner occupier & 16.8 & 25.2 & 4.2 & 13.6 & 12.6 & 17.9 & 12.3 & 18.3 \\
\hline LA tenant & 15.0 & 22.2 & 10.4 & 13.8 & 14.2 & 21.3 & 14.0 & 20.8 \\
\hline Private renter & 12.2 & 33.7 & 6.5 & 2.5 & 15.1 & 19.5 & 13.9 & 20.9 \\
\hline All & 15.3 & 26.2 & 5.9 & 12.5 & 13.6 & 19.2 & 13.1 & 19.4 \\
\hline \multicolumn{9}{|l|}{$80 y+$} \\
\hline Owner occupier & 19.7 & 44.0 & 6.3 & 20.9 & 22.2 & 32.7 & 21.2 & 33.8 \\
\hline LA tenant & 26.1 & 42.1 & 12.5 & 33.3 & 24.9 & 33.9 & 24.5 & 34.8 \\
\hline Private renter & 30.2 & 53.8 & 16.7 & 46.7 & 27.5 & 40.6 & 27.8 & 42.6 \\
\hline All & 24.2 & 45.0 & 11.1 & 29.1 & 24.2 . & 34.5 & 23.7 & 35.6 \\
\hline
\end{tabular}




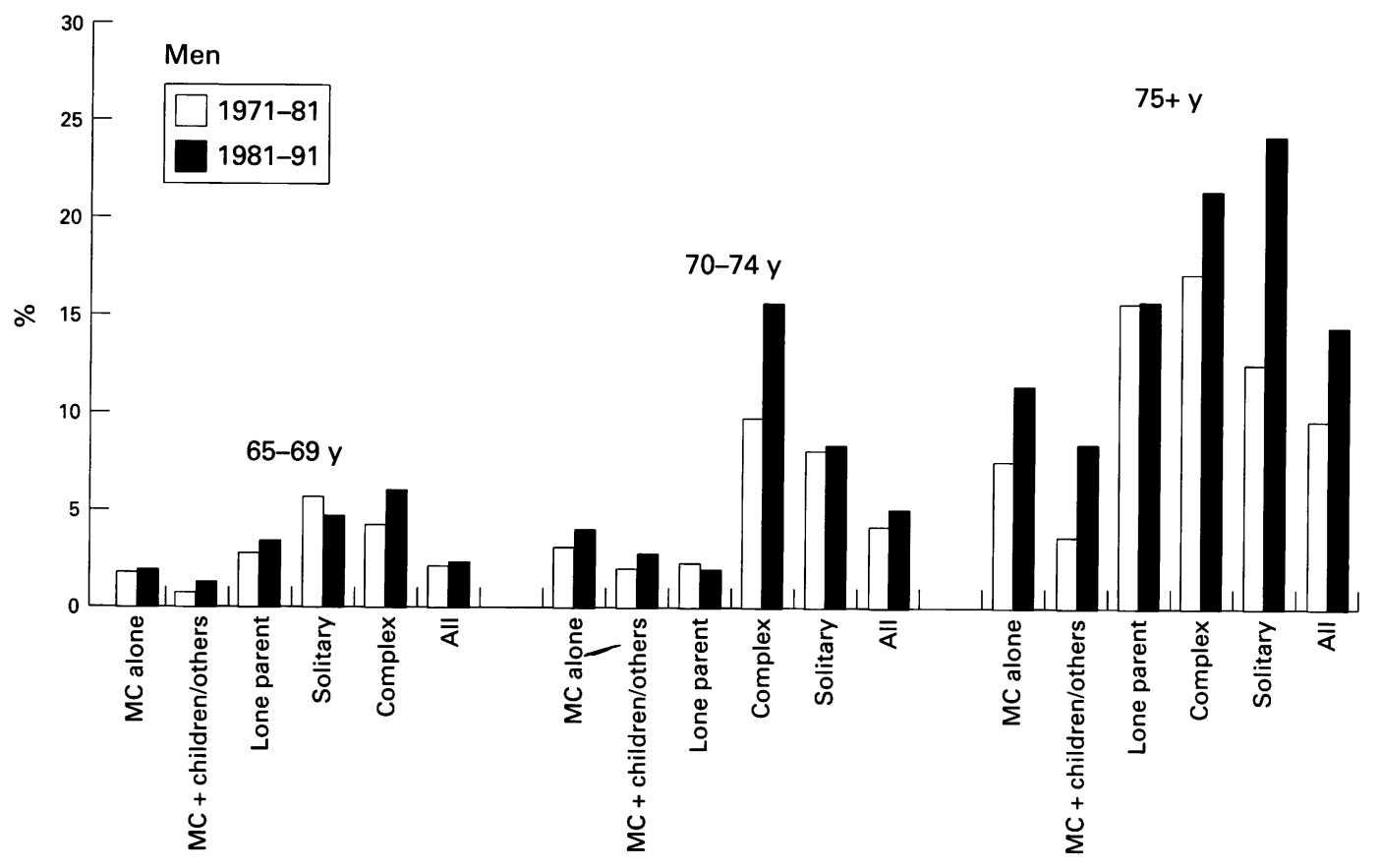

Family/household type 10 years earlier

Figure 3 Transitions to institutions in 1971-81 and 1981-91 in relation to family/household type and age at the beginning of the decade - men. (MC=married couple.)

model may be assessed by the size of the scaled deviance relative to the degrees of freedom (and of course through examination of the residuals). In the models fitted to the data for men, the marital status and age terms reduced the deviance substantially; the effect of tenure was less, although significant. A model including the age, marital status, and tenure terms together fitted the 1971-81 data reasonably well. For 1981-91, age and marital status together provided a good fit; the addition of tenure, produced a statistically significant reduction in the deviance, but the parsimony of the former model including just two terms might be preferred. The addition of the dummy term representing period was significant and roughly similar to the effect for tenure. Age, marital status, tenure, and period main effects terms produced a model which fitted the 1971-81 and 1981-91 combined data well.

The fit of these models applied to data for women was less good for the whole data set and for the 1981-91 subset, although as for the male data the independent terms all produced significant falls in the deviance. In the case of women, age had a greater effect than marital status, while the converse was true for men. While interaction effects were negligible in the male data, the fit of the models applied to female data was slightly improved by the addition of an age.marital status interaction term and, in the case of the combined data, of age.period and period.marital status terms. However, while the addition of these interaction effects produced changes that were statis-

Table 3 Scaled deviances and changes in deviance, for regression models of the proportion in private households at $t_{1}$ but in institutions at $t_{2}$ by age, marital status (MS), housing tenure, and period

\begin{tabular}{|c|c|c|c|c|c|c|c|c|c|c|c|c|}
\hline \multirow[b]{3}{*}{ Model } & \multicolumn{4}{|c|}{$1971-81$} & \multicolumn{4}{|l|}{$1981-91$} & \multicolumn{4}{|c|}{ 1971-81 and $1981-91$} \\
\hline & \multicolumn{2}{|c|}{ Scaled deviance } & \multicolumn{2}{|c|}{ Difference } & \multicolumn{2}{|c|}{ Scaled deviance } & \multicolumn{2}{|c|}{ Difference } & \multicolumn{2}{|c|}{ Scaled deviance } & \multicolumn{2}{|c|}{ Difference } \\
\hline & (D) & $d f$ & $D$ & $d f$ & (D) & $d f$ & $D$ & $d f$ & (D) & $d f$ & (D) & $d f$ \\
\hline Men & & & \multicolumn{2}{|c|}{ (from null) } & & & \multicolumn{2}{|c|}{ (from null) } & & & \multicolumn{2}{|c|}{ (from null) } \\
\hline Null & 310.9 & 26 & & & 611.3 & 26 & & & 947.2 & 53 & & \\
\hline Age & 197.0 & 24 & 113.9 & 2 & 277.8 & 24 & 333.5 & 2 & 495.1 & 51 & 452.0 & 2 \\
\hline MS & 108.4 & 24 & 202.5 & 2 & 241.3 & 24 & 369.9 & 2 & 377.6 & 51 & 569.6 & 2 \\
\hline \multirow{2}{*}{ Period } & & & & & & & \multirow{2}{*}{\multicolumn{2}{|c|}{ (from previous) }} & 922.5 & 52 & 25.0 & 1 \\
\hline & & & \multicolumn{2}{|c|}{ (from previous) } & & & & & & & \multicolumn{2}{|c|}{ (from previous) } \\
\hline Age + MS & 45.4 & 22 & 151.6 & 2 & 18.7 & 22 & 259.1 & 2 & 90.8 & 49 & 286.8 & 2 \\
\hline+ Tenure & 26.9 & 20 & 18.5 & 2 & 12.0 & 20 & 6.7 & 2 & 70.3 & 47 & 20.5 & 2 \\
\hline+ Period & & & & & & & & & 48.1 & 46 & 22.2 & 1 \\
\hline \multicolumn{13}{|l|}{ Women } \\
\hline Null & 821.5 & 35 & & & 1822.6 & 35 & & & 2794.1 & 71 & & \\
\hline Age & 215.1 & 32 & 606.4 & 3 & 288.1 & 32 & 1535.0 & 3 & 611.5 & 68 & 2183.0 & 3 \\
\hline MS & 524.8 & 33 & 296.7 & 2 & 1350.0 & 33 & 472.7 & 2 & 2066.7 & 69 & 727.4 & 2 \\
\hline Tenure & 803.2 & 33 & 18.3 & 2 & 1774.7 & 33 & 48.0 & 2 & 2743.6 & 69 & 50.6 & 2 \\
\hline Age + MS & 45.4 & 30 & 169.6 & 2 & 84.21 & 30 & 203.9 & 2 & 270.3 & 66 & 341.2 & 2 \\
\hline+ Tenure & 34.2 & 28 & 11.2 & 2 & 52.74 & 28 & 31.5 & 2 & 160.0 & 65 & 110.3 & 1 \\
\hline $\begin{array}{l}\text { + Period } \\
\text { Main effects }\end{array}$ & & & & & & & & & 119.3 & 63 & 40.8 & 2 \\
\hline $\begin{array}{l}\text { Main eftects } \\
\text { +Age.MS }\end{array}$ & 18.6 & 22 & 15.6 & 2 & 34.4 & 22 & 18.3 & 6 & 91.7 & 57 & 27.5 & 6 \\
\hline
\end{tabular}




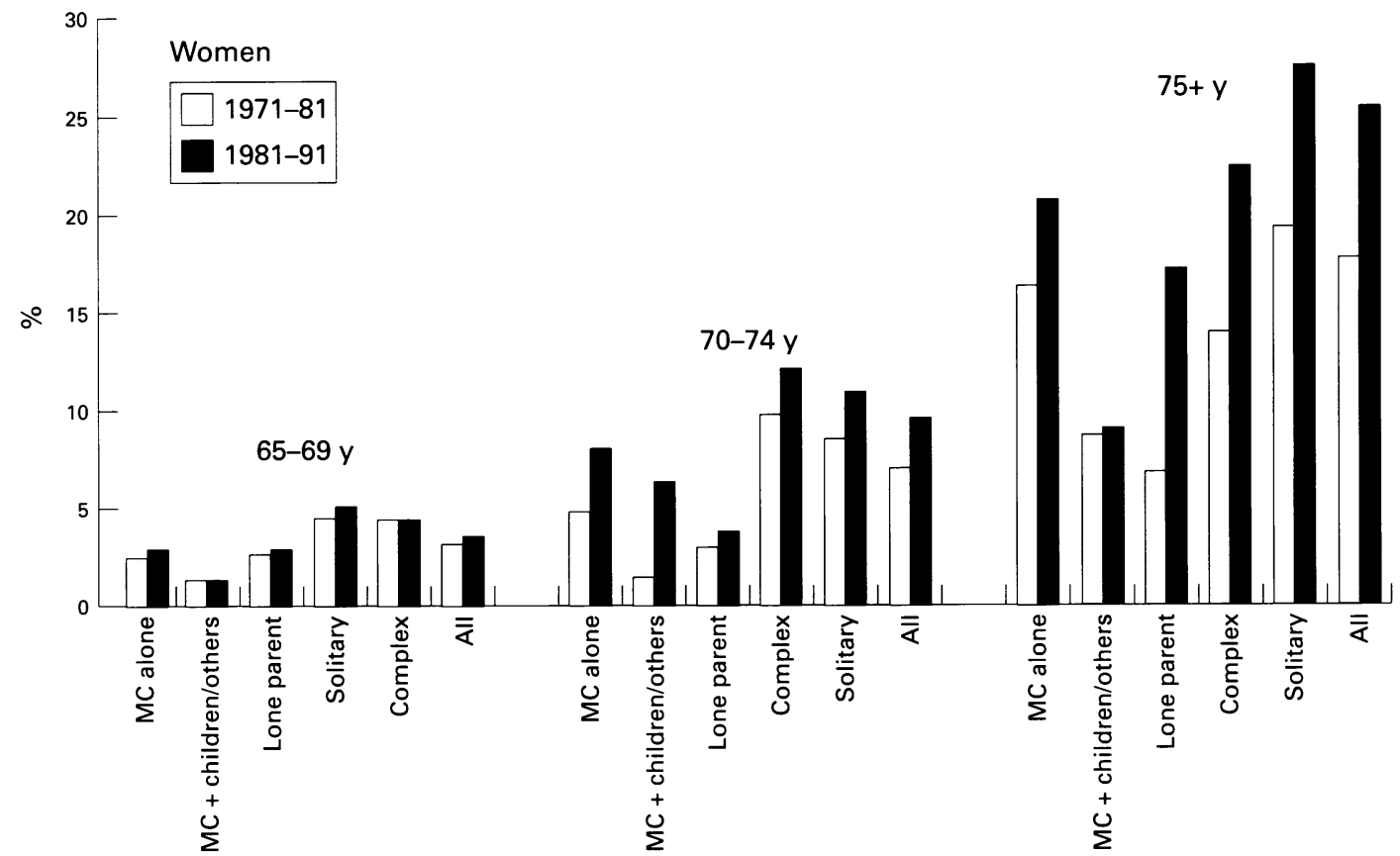

Family/household type 10 years earlier

Figure 4 Transitions to institutions in 1971-81 and 1981-91 in relation to family/household type and age at the begining of the decade - women. (MC=married couple.)

tically significant, the associated parameter estimates were small (and less than twice their standard errors) and we preferred the more parsimonious models including just main effects.

The effect of these variables in different age and sex groups is shown more clearly in the odds ratios derived from the parameter estimates $\left(B_{i}\right)$ odds ratio $=e^{\beta i}$, these, together with $95 \%$ confidence intervals are shown in table 4 for the selected main effects models including age, marital status, tenure and, where appropriate, the period indicator. It is clear that the risk associated with older age, which is substantial, was greater in the second decade. The unmarried, particularly the single, had very much higher risks of moving to an institution. As already noted, the influence of tenure was less marked, but still substantial Male tenants of privately rented accommodation in the first period had nearly twice the risk of institutionalisation as equivalent owner occupiers and a substantially elevated risk in the second period also. Local authority tenants also appear to be at a higher risk, although in the smaller male sample this difference was not statistically significant. One of the most interesting results of the analysis is the much higher odds of entry into an institution in 1981-91 compared with 1971-81. The second decade samples of men and women had respectively a $43 \%$ and $52 \%$ higher risk of transition from a private household between 1981-91 than between 1971-81.

Table 4 Odds ratios ( $\left.e^{\beta i}\right)(95 \%$ confidence intervals) for age, marital status (MS), housing tenure (and period) main effects models

\begin{tabular}{|c|c|c|c|}
\hline & $1971-81$ & $1981-91$ & 1971-81 and 1981-91 \\
\hline & OR $(95 \% C I)$ & OR $(95 \% C I)$ & OR $(95 \% C I)$ \\
\hline \multicolumn{4}{|l|}{ Men } \\
\hline \multicolumn{4}{|l|}{ Age } \\
\hline $70-74 y$ & $1.71(1.28,2.30)$ & $2.04(1.61,2.58)$ & $1.89(1.57,2.27)$ \\
\hline $75+y$ & $3.53(2.61,4.76)$ & $5.51(4.38,6.92)$ & $4.67(3.90,5.60)$ \\
\hline \multicolumn{4}{|l|}{ Marital status } \\
\hline Wid/div & $4.69(3.51,6.27)$ & $4.59(3.72,5.67)$ & $4.56(3.88,5.45)$ \\
\hline Single & $6.08(3.94,9.39)$ & $5.20(3.69,7.33)$ & $5.50(4.20,7.20)$ \\
\hline \multicolumn{4}{|l|}{ Tenure } \\
\hline LA & $1.26(0.93,1.71)$ & $1.11(0.90,1.37)$ & $1.16(0.98,1.38)$ \\
\hline Private rent & $1.90(1.43,2.53)$ & $1.41(1.09,1.82)$ & $1.61(1.33,1.94)$ \\
\hline Period 1981-91 & & & $1.43(1.23,1.67)$ \\
\hline \multicolumn{4}{|l|}{ Women } \\
\hline $70-74 y$ & $2.07(1.76,2.43)$ & $2.71(2.36,3.11)$ & $2.42(2.18,2.69)$ \\
\hline $75+y$ & $3.83(3.24,4.54)$ & $5.60(4.88,6.42)$ & $4.81(4.32,5.35)$ \\
\hline Age $80+y$ & $7.53(6.20,9.15)$ & $12.48(10.69,14.57)$ & $10.27(9.11,11.58)$ \\
\hline \multicolumn{4}{|l|}{ Marital status } \\
\hline Wid/div & $4.18(3.16,5.53)$ & $2.38(2.01,2.81)$ & $2.83(2.45,3.13)$ \\
\hline Single & $5.15(3.79,7.01)$ & $3.79(3.11,4.62)$ & $4.07(3.45,4.80)$ \\
\hline \multicolumn{4}{|l|}{ Tenure } \\
\hline LA & $1.21(1.05,1.40)$ & $1.23(1.10,1.36)$ & $1.22(1.12,1.32)$ \\
\hline Private rent & $1.25(1.08,1.45)$ & $1.41(1.24,1.60)$ & $1.33(1.21,1.48)$ \\
\hline \multirow{2}{*}{\multicolumn{3}{|c|}{$\begin{array}{l}\text { Period } 1981-91 \\
\text { Base }=65-9, \text { married, owner occupier, } 1971-81\end{array}$}} & $1.52(1.41,1.65)$ \\
\hline & & & \\
\hline
\end{tabular}

Wid/div=widowed or divorced. 


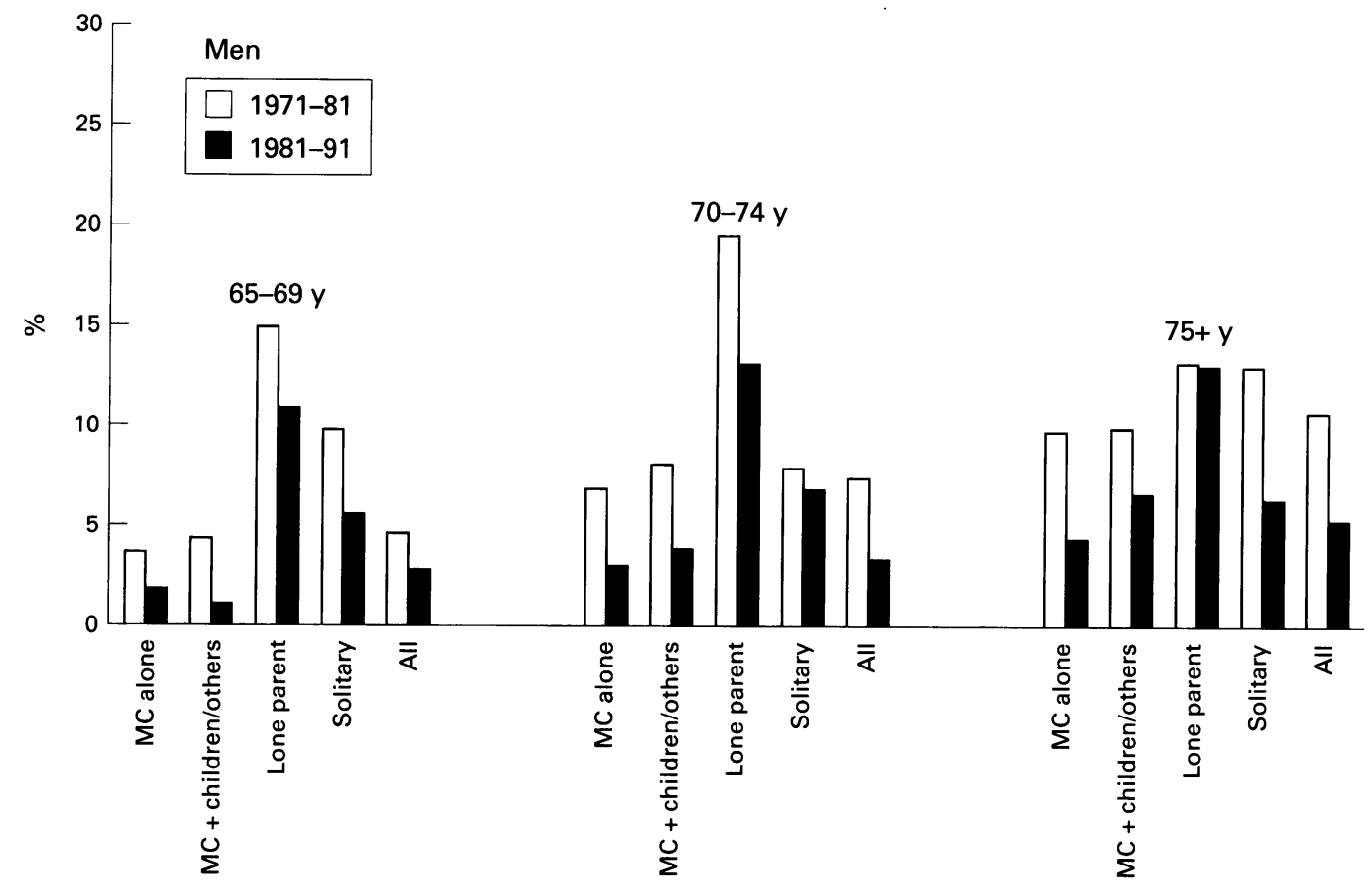

Family/household type 10 years earlier

Figure 5 Transitions to complex households in 1971-81 and 1981-91 in relation to family/household type and age at the beginning of the decade - men. (MC=married couple.)

AGE, FAMILY/HOUSEHOLD TYPE, AND HOUSING TENURE

Figures 3 and 4 show for men and women who in 1971 or 1981 lived in private households, the proportions of survivors who were resident in non-private households 10 years later according to the age group and family/household type at the start of the decade. In both decades, and in all age groups, transition rates were higher for those initially not living in families (alone or in complex households) and lowest for those living with a spouse and never-married children and/or others. A series of models were fitted to these data following the same procedure described for the previous analyses. The results of this (not shown but available from the authors) showed the inclusion of a household/ family term substantially reduced the deviance and that models including this term, together with age and housing tenure variables, produced a good fit to some subsets of the data, such as those for females in 1981-91 (D 43.3; $\chi^{2} 42.5$, df 36). Odds ratios derived from the parameter estimates of the models fitted to data for the two decades are shown in table 5 . These

Table 5 Odds ratio ( $e^{\beta i}$ ) (95\% confidence intervals) for age, household/family type housing tenure, and period main effects models

\begin{tabular}{|c|c|c|c|}
\hline & & Men & Women \\
\hline & & OR $(95 \% C I)$ & $O R(95 \% C I)$ \\
\hline \multicolumn{4}{|l|}{ Age } \\
\hline $70-4 y$ & & $2.11(1.76,2.53)$ & $2.48(2.24,2.75)$ \\
\hline $75+y$ & & $5.51(4.61,6.58)$ & $6.48(5.87,7.15)$ \\
\hline \multicolumn{4}{|l|}{ House/family type } \\
\hline Married couple & . & $0.43(0.36,0.51)$ & $0.64(0.58,0.70)$ \\
\hline Married couplet & & $0.31(0.23,0.42)$ & $0.32(0.25,0.41)$ \\
\hline Lone parent & & $0.56(0.33,0.92)$ & $0.42(0.35,0.51)$ \\
\hline Complex & & $1.31(1.04,1.64)$ & $0.84(0.75,0.93)$ \\
\hline \multicolumn{4}{|l|}{ Tenure } \\
\hline LA & & $1.27(1.07,1.51)$ & $1.19(1.10,1.30)$ \\
\hline Private rent & & $1.62(1.34,1.95)$ & $1.35(1.22,1.49)$ \\
\hline Period 2 & & $1.33(1.15,1.56)$ & $1.46(1.35,1.58)$ \\
\hline \multicolumn{4}{|c|}{ Base $=65-69$, solitary, owner occupier } \\
\hline
\end{tabular}

models applied to the combined data for both decades fitted the data less well than those including marital status, but the fit showed a higher risk for those living alone or in complex households and, as before, for older age groups, tenants, and in the second decade. Household/family type, of course, relates to domestic situation at the start of a decade, in many cases this would have changed, for example as a result of widowhood before the next census.

A complete review of changes in transition rates between different household types is beyond the scope of this paper, but this increase in the extent of institutionalisation in the second decade raises the question of whether transitions to other types of supported environments, such as the households of relatives, became less common. As shown in figures 5 and 6 this indeed appears to be the case. The proportion of elderly people moving to complex households from other types of private household was much lower 1981-91 than in the 1971-81 period.

\section{Discussion}

The promotion of community rather than institutional care for disabled elderly people has been an avowed aim of Government policy for most of the post 1948 period. ${ }^{48}{ }^{49}$ Despite this, the results presented here show that after adjustment for related sociodemographic variables, the risk of moving from a private to a non-private household was close to $50 \%$ higher in 1981-91 than in 1971-81.

A number of potentially important factors, such as availability of children and health status, could not be allowed for in this analysis as data on them were not available for both decades. However, given the changes in past nuptiality and fertility patterns, the proportion 


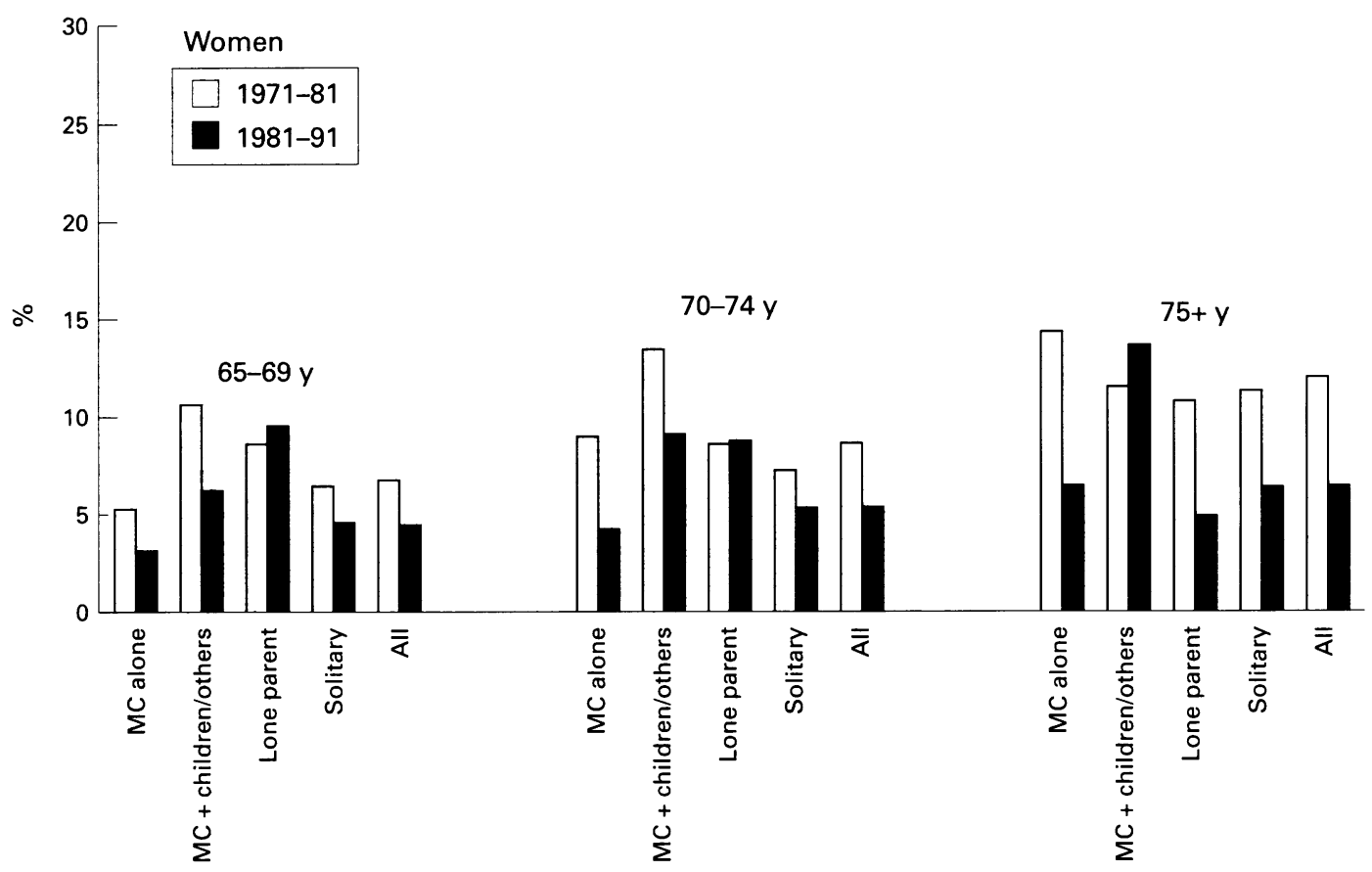

Family/household type 10 years earlier

Figure 6 Transitions to complex households in 1971-81 and 1981-91 in relation to family/household type and age at the begining of the decade - women. (MC=married couple.)

of childless people in the second decade would certainly have been lower than in the earlier period. Trends in health status are more controversial, not least because of the exclusion of the institutional population from most health surveys and the consequent need to make various assumptions about their health. What evidence there is suggests that although there appears to have some increase in the reported prevalence of mild and moderate health problems and disabilities (perhaps because of higher health expectations), the prevalence of more serious disabilities has fallen. ${ }^{40-52}$ Results from the special sections on elderly people periodically included in the general household survey, for example, show that in $1991,80 \%$ of men and $75 \%$ of women in private households were able to bathe themselves, feed themselves, get in and out of bed, and get to the toilet without the help of another person. In 1980 the equivalent percentages were only $69 \%$ and $64 \% .^{3}$ Of course, as we have shown here, the proportion of this age group in institutions increased during this period, so the later estimate is biased downwards more than that for 1980 . However, calculations adjusted to allow for the institutional population also show a fall in the extent of inability to undertake personal care tasks without help. ${ }^{52}$ Similar results, showing decreases in serious disability, have been reported from a number of other European countries. ${ }^{53}$ In short, it is likely that had it been possible to control for these factors, the divergence between the two decades might have appeared even greater. This does not in itself imply misuse of institutional care in the 1980s. In comparison with other developed countries Britain has a rather low rate of provision of institutionalisation care, even today. ${ }^{40}$ This suggests a closer relationship with health related variables than may have been the case in the past. In Townsend's classic study, ${ }^{54}$ for example, poverty and homelessness seemed in some cases to have prompted admission to residential care.

In terms of differentials in transitions to institution care, the relationship between age and such a transition was stronger in the second decade considered here. Other differences in risks of transition were perhaps surprisingly similar. In 1981-91, as in the previous decade, tenants of privately rented accommodation had the highest odds of moving to an institution. However, because of changes in the distribution of the older population in relation to housing tenure, they constituted a lower proportion of all those moving to institutions in the second period. In 1991, 18\% of elderly residents in non-private households had been private tenants 10 years earlier-the equivalent proportion in 1981 was $26 \%$. Earlier analyses failed to find an association between poor housing conditions and increased risk of institutionalisation ${ }^{37}$ and it was hypothesised that perhaps the greater insecurity of privately renting tenants was a relevant factor. It seems likely that this still may be a factor. The OPCS 1990 survey of private renters $^{55}$ showed that $23 \%$ of elderly private tenants who lived alone had types of tenancy which offered little or no security ( a large proportion of these tenants were in fact living in rent free accommodation.) However, much of the relationship between housing tenure and transition rates to institutions is likely to be an indirect one; tenure is known to be strongly associated with health status and the data set used here includes no direct measure of health.

Overall, this paper shows that sociodemographic differentials in the risks of institutionalisation are substantial and that, allowing for these, these risks were higher 1981-91 than in 
1971-81. This suggests some change in the threshold at which older people choose institutional care and/or a change in the choice of institutionalisation rather than family care. Such "choices" may of course be constrained by the willingness of relatives to provide care and the availability of domiciliary services. It is interesting that the extent of transitions to complex households declined so markedly in the same period. Moreover, the proportion of married people who moved to institutions, while much lower than that of people of other marital statuses, increased quite substantially between 1971-81 and 1981-91 with the result that odds ratios for the single and widowed/ divorced were slightly lower in the second decade. It seems highly probable that increases in the supply of institutional care and perverse incentives to choose this rather than care at home care are implicated in this shift from, rather than to, care in the community. The suggestion of a changing shift in the balance of institutional and family care is a worrying one for policy makers now employed in trying to promote care in the community.

We would like to thank ONS for permission to use the ONS Longitudinal Study; Kevin Lynch and colleagues of the LS support team at SSRU, The City University, for advice and help including abstracting relevant tabulations, and Leyla Osman (KCL) for help in preparing the manuscript and artwork.

Funding: The LS support team at the City University is supported by the Economic and Social Research Council (UK), grant reference no $\mathrm{H} / 507 / 26 / 5001$.

Conflicts of interest: none.

1 House of Commons Select Committee on Health. Longterm care: future provision and funding. Minutes of evidence, 1995-96. London: HMSO, 1995.

2 Pollard JH. Long-term care in selected countries: demographic and insurance perpsectives. Zeitschrift für Bevölkerungswissenschaft 1995;20:293-310

3 Social Statistics Research Unit. OPCS longitudinal study user manual. London: City University, 1990.

4 Grundy E. Population review: (5) The population aged 60 and over. Popul Trends 1996;84:14-20.

5 Goldman N, Korenman S, Weinstein R. Marital status and Goldman N, Korenman S, Weinstein R. Marital status and
health among the elderly. Soc Sci Med 1995;40(12):1717-

30

Murphy M, Glaser K, Grundy EMD. Marital status and limiting long-term illness in Great Britain. Fournal of Marriage and the Family 1997;59:156-64.

7 Grundy EMD, Arie T. Institutionalization and the elderly: international comparisons. Age Ageing 1984;13:129-37.

8 Börsch-Supan AH. A dynamic analysis of household dissolution and living arrangement transitions by elderly Americans. In: Wise DA, ed. Issues in the economics of aging. Chicago: National Bureau of Economic Research, 1990.

Siegel JS. A generation of change: a profile of America's older population. New York: Russell Sage Foundation, 1992.

10 van Solinge $\mathrm{H}$. Living arrangements of non-married elderly van Solinge $\mathrm{H}$. Living arrangements of non-married elderly
people in the Netherlands in 1990. Ageing and Society people in the Neth

11 Kobrin FE. The primary individual and the family: changes in living arrangements in the United States since 1940 fournal of Marriage and the Family 1976;38:233-8.

12 Pampel FC. Trends in living alone among the elderly in Europe. In: Rogers A ed. Elderly migration and population redistribution. London: Belhaven Press, 1992.

13 Keilman N. Recent trends in family and household composition in Europe. European fournal of Population 1987;3: 297-325.

14 Grundy E. Household change and migration among the elderly in England and Wales. Espace, Population, Societies 1987;1:109-23.

15 Murphy M, Grundy EMD. Co-residence of generations and household structure in Britain: aspects of change in the 1980s. In: Becker HA, Hermkens PLJ, eds. Solidarity of generations; demographic, economic and social change and its
consequences. Vol 11. Amsterdam: Thesis Publisher, 1993 .

16 Wolf DA. Changes in the living arrangements of older women: an international study. Gerontologist 1995;35(6): 724-31.

17 Kramarow EA. The elderly who live alone in the United States: historical perspectives on household change. States: historical perspectives

18 Dolinsky AL, Rosenwaike I. The role of demographic factors in the institutionalization of the elderly. Research on Aging 1988;10(2):235-57.
19 Shapiro E, Tate R. Predictors of long-term care facility use among the elderly. Am f Public Health 1985;4:11-19.

20 Worobey JL, Angel RJ. Functional capacity and living arrangements of unmarried elderly persons. $\mathcal{f}$ Gerontol arrangements of un

21 Branch LG, Jette AM. A prospective study of long-term care institutionalization among the aged. Am $\mathcal{f}$ Public Health 1982;72(12):1373-9.

22 Mutchler JE, Burr JA. A longitudinal analysis of household and nonhousehold living arrangements in later life. Demography 1991;28(3):375-90.

23 Wolf DA. The elderly and their kin: patterns of availability and access. In: Martin LG, Preston SH, eds. Demography of aging. Washington DC: Academy Press, 1994:1259-76.

24 Wolf DA, Soldo BJ. Household composition choices of older unmarried women. Demography 1988;25(3):387-403.

25 Speare A, Avery R, Lawton L. Disability, residential mobility, and changes in living arrangements. $f$ Gerontol 1991;46(3):S133-42.

26 Spitze G, Logan JR, Robinson J. Family structure and changes in living arrangements among elderly nonmarried parents. F Gerontol 1992;47(6):S289-96.

27 Rosenwaike I. The extreme aged in America: a portrait of an expanding population. Westport, Connecticut: Greenwood Press, 1985.

28 Soldo BJ. The living arrangements of the elderly in the near future. In: Kiesler SG, Morgan JN, Oppenheimer VK, eds. Ageing, social change. New York: 1981.

29 Palmore E. Total chance of institutionalization among the aged. Gerontologist 1976;16(6):504-7.

30 Townsend $\mathrm{P}$, Wedderburn $\mathrm{D}$. The aged in the welfare state: the interim report of a survey of persons aged 65 and over in Britain, 1962 and 1963. London: G Bell; 1965.

31 Department of Health and Social Security. The census of residential accomodation for the elderly and for the physically handicapped. London: HMSO, 1975.

32 Hodkinson E, McCafferty SJ, Stout RW. Disability and dependency in elderly people in residential and hospital care. Age Ageing 1988;1 7:147-54.

33 MacLennan WJ, Isles FE, McDougall S, Keddie E. Medical and social factors influencing admission to residential care. BMF 1984;288:701-3.

34 Darton RA. PSSRU survey of residential accomodation for the elderly, 1981: characteristics of the residents. Discussion Paper No 426 Canterbury: Personal Social Services Research Unit, University of Kent, 1986.

35 Martin J, Meltzer H, Elliot D. OPCS surveys of disability in Great Britain. Report 1: the prevalence of disability among adults. London: HMSO, 1988.

36 Harrop A, Grundy E. Geographic variations in moves into institutions among elderly people in England and Wales. Urban Studies 1991;28:83-104.

37 Grundy E. Socio-demographic variations in rates of movement into institutions among elderly people in movement into institutions among elderly people in tality data 1971-1985. Population Studies 1992;46:65-84

38 Office of Population Censuses and Surveys. Living in Britain: general household survey 1994. London: HMSO, 1996.

39 Meredith B. The community care handbook: the reformed system explained. London: Age Concern England, 1995.

40 Laing W. Financing long-term care: the crucial debate. London: Age Concern England, 1996.

41 Grundy E. Community care for the elderly 1976-84. BMF 1987;294:626-9.

42 Department of Health and Social Security. Caring for people, community care in the next decade and beyond. London: HMSO, 1989.

43 Hattersley L, Creeser R. Longitudinal study 1971-1991: history, organisation and quality of data. $L S$ no 7. HMSO, 1995.

44 Fox AJ, Goldblatt PO. Longitudinal study: sociodemographic and mortality differentials. London: HMSO, 1982 .

45 Goldblatt PO. Mortality and social organisation. Longitudinal study series no 6. London: HMSO, 1990.

46 Hattersley L. Data quality: linkage and coverage. The OPCS longitudinal study update, 12, 2-5. SSRU, The City University, London, 1995.

47 Aitkin M, Anderson D, Francis B, Hinde J. Statistical modelling in GLIM. Oxford Science Publications. Oxford: Clarendon Press, 1989.

48 Boucher CA. Surveys of services available to the chronic sick and elderly 1954-1955. Reports on public health and medical subjects no 98. London: HMSO, 1957.

49 Department of Health and Social Security. Priorities for health and personal social services in England: a consultative document. London: HMSO, 1976.

50 Grundy E. Future patterns of morbidity among the elderly. In: Caird FI, Grimley J, eds. Advanced geriatric medicine. Bristol: John Wright, 1987.

51 Dunnell K. Population review (2) Are we healthier? Popul Trends 1995;82:12-8.

52 Bebbington AC, Darton RA. Healthy life expectancy in England and Wales: recent evidence. Discussion Paper 1205. Canterbury: Personal Social Services Research Unit, University of Kent at Canterbury, 1996.

5353 Boshaizen HC, van de Water HPA. An international comparison of health expectancies. Leiden: TNO Health Research, 1994.

54 Townsend P. The last refuge. A survey of residential institutions and homes for the aged in England and Wales. London: 1962. 55 Rauta I, Pickering A. Private renting in England 1990. London: HMSO, 1992. 